\title{
Effects of Exercise Training on Pulmonary Mechanics and Functional Status in Patients With Prolonged Mechanical Ventilation
}

\author{
Yen-Huey Chen MSc PT, Hui-Ling Lin MSc RRT RN, Hsiu-Feng Hsiao MBA RT, \\ Lan-Ti Chou MSc RT, Kuo-Chin Kao MD, Chung-Chi Huang MD, and Ying-Huang Tsai MD
}

\begin{abstract}
BACKGROUND: The functional status and outcomes in patients with prolonged mechanical ventilation (PMV) are often limited by poor endurance and pulmonary mechanics, which result from the primary diseases or prolonged time bedridden. We evaluate the impact of exercise training on pulmonary mechanics, physical functional status, and hospitalization outcomes in PMV patients. METHODS: Twenty-seven subjects with PMV in our respiratory care center (RCC) were divided randomly into an exercise training group $(n=12)$ and a control group $(n=15)$. The exercise program comprised 10 sessions of exercise training. The measurement of pulmonary mechanics and physical functional status (Functional Independence Measurement and Barthel index) were performed pre-study and post-study. The hospitalization outcomes included: days of mechanical ventilation, hospitalization days, and weaning and mortality rates during RCC stay. RESULTS: The training group had significant improvement in tidal volume $(143.6 \mathrm{~mL}$ vs $192.5 \mathrm{~mL}, P=.02)$ and rapid shallow breathing index after training (162.2 vs 110.6, $P=.009)$. No significant change was found in the control group except respiratory rate. Both groups had significant improvement in functional status during the study. However, the training group had greater changes in FIM score than the control group (44.6 vs 34.2, $P=.024)$. The training group also had shorter RCC stay and higher weaning and survival rates than the control group, although no statistical difference was found. CONCLUSIONS: Subjects with PMV in our RCC demonstrated significant improvement in pulmonary mechanics and functional status after exercise training. The application of exercise training may be helpful for PMV patients to improve hospitalization outcomes. Key words: exercise training; prolonged mechanical ventilation; activities of daily living; pulmonary mechanics; respiratory care center; outcomes. [Respir Care 2012;57(5):727-734. (C) 2012 Daedalus Enterprises]
\end{abstract}

\section{Introduction}

Mechanical ventilation (MV) is a necessary treatment for patients with respiratory failure in ICUs. As patients recover from acute illness, some may have difficulties in

Ms Chen, Ms Lin, Ms Hsiao, Dr Kao, Dr Huang, and Dr Tsai are affiliated with the Department of Respiratory Care, Chang Gung University, Taoyuan, Taiwan. Ms Hsiao, Ms Chou, and Dr Kao are affiliated with the Division of Respiratory Therapy; Dr Kao, Dr Huang, and Dr Tsai are affiliated with the Division of Pulmonary and Critical Care Medicine, Chang Gung Memorial Hospital, Taoyuan, Taiwan. Ms Chou is also affiliated with the Department of Respiratory Care, Chang Gung Institute of Technology, Taoyuan, Taiwan. RT: Certified respiratory therapist in Taiwan

This study was supported by grant NMRP0061 from the National Science Council, Taipei, Taiwan. weaning from MV and become prolonged MV (PMV) dependent. Patients on PMV are often transferred to subacute care units, such as the respiratory care center (RCC), for continued care and further mechanical ventilator weaning. ${ }^{1}$

However, various complications may occur with PMV and hinder the weaning process. Patients on PMV are often deconditioned due to the impact of underlying diseases, side effects from medications, and prolonged time bedridden. After prolonged bed rest, PMV patients may

\footnotetext{
Correspondence: Chung-Chi Huang MD, Division of Pulmonary and Critical Care Medicine, Chang Gung Memorial Hospital, 5 Fu-Hsin Street, Gweishan, Taoyuan, Taiwan 333. E-mail: cch4848@adm.cgmh.org.tw.
}

DOI: $10.4187 /$ respcare. 01341 


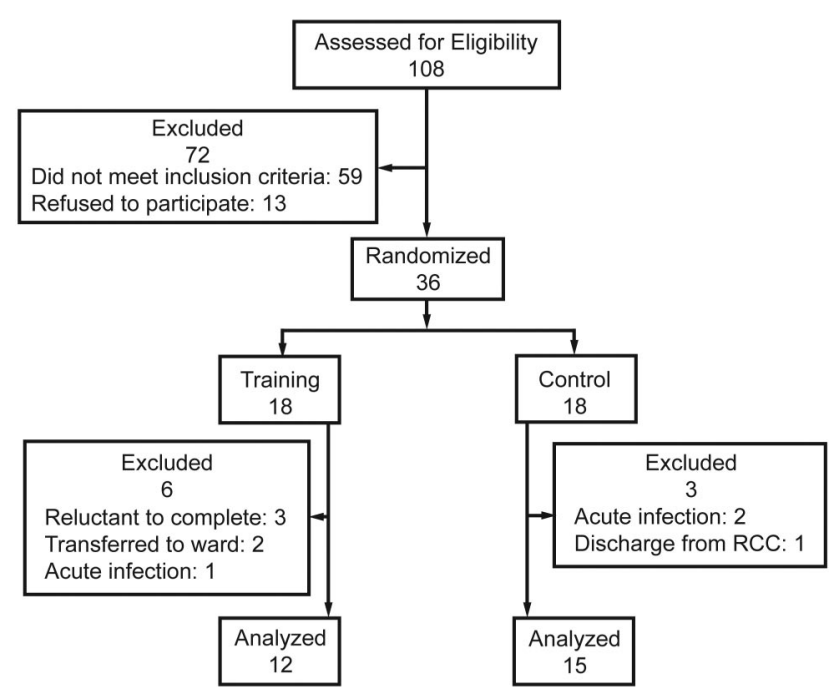

Fig. 1. Flow chart of subject participation and analysis. $\mathrm{RCC}=$ respiratory care center.

suffer from respiratory muscle weakness, limb muscle atrophy, and decreased ability to perform activities of daily living (ADL). ${ }^{2}$ The complications of PMV, such as barotrauma and/or ventilator-induced diaphragm dysfunction can also further impair pulmonary mechanics. These factors together may lead to increased mortality rate, MV weaning failure rate, hospital stay, and impaired physical functional status in the PMV population.

There is compelling evidence that exercise training can improve the performance of ADL and quality of life in patients with chronic pulmonary dysfunction. ${ }^{3,4}$ The mechanisms of improvement are not precisely known and are probably multifactor. The relative importance of potential physiologic contributing factors such as increased aerobic capacity or enhanced ventilatory and peripheral muscle function have been reported. ${ }^{5,6}$ Studies also showed that hospitalized patients with pulmonary dysfunction may benefit from exercise training, by decreasing days of hospitalization and the risks of complications. ${ }^{7}$ Although there have been numerous reports of improved outcomes with exercise training on patients with pulmonary dysfunction, few controlled studies have discussed the effects of exercise training on PMV patients.

The purpose of this study was to evaluate the effects of an exercise training program on pulmonary mechanics, physical functional status, and hospitalization outcomes in terms of RCC stay, mechanical ventilator weaning rate, and mortality rate in patients requiring PMV in an RCC.

\section{Methods}

\section{Subjects}

We enrolled patients from our RCC in Chang Gung Memorial Hospital, Taiwan. Once subjects were medically

\section{QUICK LOOK}

\section{Current knowledge}

Prolonged mechanical ventilation (PMV) is associated with deconditioning, muscle weakness, and diminished capacity to perform activities of daily living.

\section{What this paper contributes to our knowledge}

Patients requiring PMV demonstrate significant improvement in pulmonary mechanics and functional status after exercise training. Exercise training may be helpful for PMV patients to improve outcomes.

stable and their MV settings were changed from continuous mandatory ventilation mode to pressure support mode, we evaluated their eligibility to participate in the study. To meet the criteria, patients had to be receiving MV for $>6$ hours a day for $>21$ days, and had previously failed to wean from a mechanical ventilator in the ICU; had to be alert and able to cooperate with training personnel; had to be medically stable (arterial blood gas $\mathrm{pH} 7.35-7.45$, $\mathrm{P}_{\mathrm{aO}_{2}} \geq 60 \mathrm{~mm} \mathrm{Hg}$ on $\mathrm{F}_{\mathrm{IO}_{2}} \leq 0.40, \mathrm{P}_{\mathrm{aCO}_{2}} 40 \pm 5 \mathrm{~mm} \mathrm{Hg}$; for patients with COPD who had been chronically hypercapnic and had well tolerated the ventilator support, a $\mathrm{P}_{\mathrm{aCO}}$ value up to $55 \mathrm{~mm} \mathrm{Hg}$ was acceptable); had an absence of symptoms and/or signs of infection; and were hemodynamically stable. Exclusion criteria included cancer, acute lung or systemic infection, hemodynamic instability, or a severe medical condition affecting exercise performance (eg, neurologic disease, musculoskeletal limitations, and recent surgery). The research protocol was approved by the institute's ethics committee and signed, informed consent was obtained from each subject or his/ her nearest relative. Figure 1 shows a flow diagram of the type according to the guidelines of the Consolidated Standards of Reporting Trials (CONSORT).

\section{Study Design}

This study had a randomized, single-blinded, and prospective design. Randomization was preceded by using sequential sealed envelopes, which were prepared by an independent investigator before patient recruitment. Another investigator took a random envelope from the prepared box for each patient, and the patients were then assigned into exercise training group or control group according to the label in the envelope. The training group subjects received the exercise training program, consisting of cardiopulmonary endurance training, muscle strengthening, and stretching exercises, lasting 30-40 min/session, 4-6 sessions/week for 10 sessions. The subjects in 
the control group received the same medical treatment as did the training group, except for exercise training. After completing basic data collection, an investigator who was blinded to group allocation measured pulmonary mechanics at 3 time points: before the study, in the middle of the study (the day after the subject completed his or her 5th session), and at end of the study. The same investigators also assessed the subjects' physical functional status before and after the study. The hospitalization outcomes of subjects who participated in the study were followed until they were discharged from the RCC.

\section{Exercise Training Program}

The exercise training program consisted of 10 exercise training sessions supervised by an experienced physical therapist. The training program included:

- Stretching exercises consisted of cervical, upper limb, and upper chest stretching.

- Muscle strengthening exercises included respiratory muscle and arm muscle strengthening exercise. When stretching exercise were well tolerated, the training session then progressed to resisted arm activities (with weights of $0-500 \mathrm{~g}$ on the upper arms), depending on the subject's tolerance. Respiratory muscle training was performed by putting a weight $(0.5-2 \mathrm{~kg}$ sand bag) on the subject's abdomen while he or she lay on the bed.

- Cardiopulmonary endurance exercise. Subjects progressed to a cardiopulmonary endurance exercise on a cycle ergometer (APT-5, Tzora, Kibbutz Tzora, Israel) once they could tolerate upright positions for more than 1 hour without abnormal signs or symptoms. Training intensity was targeted at $60-80 \%$ of age-predicted maximal heart rate or at the level of symptom limitation, on the basis of a Borg scale rating of 3-5. Intermittent and short-term periods of rest were allowed for subjects to achieve the goal of a total of 15-25 min exercise session.

During exercise training, the vital signs and electrocardiogram were continuously monitored through the bedside computerized monitoring system (Philips Medizin System, Boblingen, Germany) for research staff to adjust the contents of the training program according to the exercise response of the subjects. Exercise was stopped if the subject presented the following intolerance signs and/or symptoms: systolic blood pressure $\geq 200 \mathrm{~mm} \mathrm{Hg}$, mean arterial blood pressure $\leq 65 \mathrm{~mm} \mathrm{Hg}$ or $\geq 110 \mathrm{~mm} \mathrm{Hg}$; tachycardia or bradycardia; abnormal electrocardiogram waveform; respiratory rate $\geq 40$ breaths $/ \mathrm{min}$ or $\leq 5$ breaths $/ \mathrm{min}$; an oxygen saturation drop of $>10 \%$; or an overall oxygen saturation $<88 \%$.

\section{Outcomes Measurements}

The primary outcome was physical functional status. The secondary outcomes were pulmonary mechanics and hospitalization during RCC stay.

\section{Physical Functional Status Measurements}

The physical functional status was represented as the capability of performing ADL. We evaluated the ADL level of each subject using the Barthel index and the Functional Independence Measurement (FIM) before and after the study period. The Barthel index is composed of a 10-item questionnaire designed to evaluate independence during activities for patients of all populations. This questionnaire includes questions about the subject's abilities in performing eating, personal hygiene, toilet, bathing, ambulation, climbing stairs, dressing, and bowel movement control. ${ }^{8}$ The FIM consists of 6 components, including self-care (dress, nutrition, etc), transfer (transfer to chair, toilet, bed), ambulation (walking, climbing stairs), communication (comprehension and expression), social recognition (memory, problem solving), and personal hygiene..$^{9,10}$ Subjects were scored from "totally dependent" to "completely independent," and lower scores represented maximal disability. The reliability and validity of the questionnaires have been reported in various research reports. ${ }^{11-13}$

\section{Pulmonary Mechanics Measurements}

Tidal volume $\left(\mathrm{V}_{\mathrm{T}}\right)$, minute volume, respiratory muscle strength (maximal inspiratory pressure), and respiratory rate were measured with a mechanics monitor (Respiradyne II, Sherwood/Covidien, Boulder, Colorado). The rapid shallow breathing index (RSBI) was calculated as respiratory rate divided by $\mathrm{V}_{\mathrm{T}}$ and recorded as an index for the pulmonary mechanics and weaning procedure.

\section{Hospitalization Outcomes}

Subjects who participated in this study were followed up until discharged from the RCC. The following variables were recorded and assessed as hospitalization outcomes: the duration of RCC stay, the days of MV application during RCC, the survival rate, and the MV weaning rate. Weaning from MV was considered successfully if the subject was free from MV continuously for $>5$ days.

\section{Sample Size Calculation}

The sample size was calculated on the basis of observations from a previous study that used the FIM score. ${ }^{10}$ On the basis of those results, the mean difference between admission and discharge statuses was 18.3 and the SDs 
were 18.5 versus 22.4 , so that a sample size of 40 subjects would be needed for $80 \%$ power and a 2 -sided significance level of .05.

\section{Statistics Analysis}

Data analysis was performed with software (SPSS version 12.0, SPSS, Chicago, Illinois). Descriptive data are presented as mean $\pm \mathrm{SD}$. Within group differences were evaluated using 1-way repeated measures analysis of variance (general linear model) for the measurements of pulmonary mechanics at different time points (pre-, mid-, and post-study). The difference in pulmonary mechanics, functional status, days of MV, and RCC stay between the 2 groups were compared by 2 -sample $t$ tests. A chi-square test was used to analyze frequency distributions of mechanical ventilator weaning and survival rates.

\section{Results}

Thirty-six subjects were recruited into the study from January 2002 to June 2003. During the study period, 6 subjects in the training group dropped out of the study: 3 subjects were reluctant to continue the training program, 2 subjects were transferred to a ward before completing the program, and 1 subject suffered from an acute pulmonary infection, stopped training, and did not return to the program. In the control group, 2 subjects dropped out of the study due to episodes of acute infection. One subject was discharged from the RCC during the study period (see Fig. 1).

\section{Baseline Characteristics}

Table 1 summarizes the demographic and clinical characteristics of the participating subjects. Twelve subjects (5 women and 7 men) completed the training program, while 15 subjects ( 8 women and 7 men) participated in the control group. The mean ages in the training and control groups were 64.9 and 66.5 years old, respectively. COPD and congestive heart failure were the major diagnoses in both groups.

\section{Effects of Exercise Training on Pulmonary Mechanics Measurements}

The comparisons of pulmonary mechanics between the training and control groups are presented in Table 2. No significant difference was found between the 2 groups in the initial measurement, except that the $\mathrm{V}_{\mathrm{T}}$ in the training group was smaller than that of the control group $(143.6 \pm 79.4 \mathrm{~mL}$ vs $230 \pm 95.6 \mathrm{~mL}, P=.04)$. After exercise training, the training group showed a significant
Table 1. Characteristics of Patients in the Training and Control Groups

\begin{tabular}{|c|c|c|}
\hline & $\begin{array}{c}\text { Training } \\
\text { Group } \\
(n=12)\end{array}$ & $\begin{array}{c}\text { Control } \\
\text { Group } \\
(n=15)\end{array}$ \\
\hline Age, y & $64.9 \pm 21.3$ & $66.5 \pm 18.7$ \\
\hline Female, no. $(\%)$ & $5(41.7)$ & $8(53.3)$ \\
\hline Male, no. (\%) & $7(58.3)$ & $7(46.7)$ \\
\hline Albumin, $\mathrm{g} / \mathrm{dL}$ & $2.8 \pm 0.4$ & $2.3 \pm 0.3$ \\
\hline $\mathrm{P}_{\mathrm{aO}_{2}}, \mathrm{~mm} \mathrm{Hg}$ & $90.6 \pm 24.6$ & $82.3 \pm 11.9$ \\
\hline $\mathrm{P}_{\mathrm{aCO}_{2}}, \mathrm{~mm} \mathrm{Hg}$ & $47.7 \pm 4.3$ & $47.2 \pm 8.0$ \\
\hline $\mathrm{pH}$ & $7.44 \pm 0.02$ & $7.43 \pm 0.34$ \\
\hline \multicolumn{3}{|l|}{ Diagnosis, no. (\%) } \\
\hline Idiopathic pulmonary fibrosis & $1(8.3)$ & 0 \\
\hline Spinal cord injury & $2(16.7)$ & 0 \\
\hline Congestive heart failure & $2(16.7)$ & $4(26.7)$ \\
\hline COPD & $3(25.0)$ & $3(20.0)$ \\
\hline Pneumoconiosis & $2(16.7)$ & $1(6.7)$ \\
\hline Sepsis & 0 & $2(13.3)$ \\
\hline Pneumonia & $2(16.7)$ & $2(13.3)$ \\
\hline Bronchiectasis & 0 & $2(13.3)$ \\
\hline Other medical disease & 0 & $1(6.7)$ \\
\hline \pm values are mean \pm SD & & \\
\hline
\end{tabular}

improvement in $\mathrm{V}_{\mathrm{T}}(143.6 \pm 79.4 \mathrm{~mL}$ vs $192.5 \pm 75.0 \mathrm{~mL}$, $P=.02)$ in the post-study measurement, compared to their baseline performance. The mid-study RSBI was also significantly decreased, when compared to pre-study measurements in the training group (110.6 \pm 31.5 vs $162.2 \pm 70.1, P=.009)$. The control group showed no significant difference in pulmonary mechanics between pre-study and post-study measurements, except for respiratory rate (27.6 vs 24.8 breaths $/ \mathrm{min}, P=.031$ ).

\section{Effects of Exercise Training on Physical Functional Status}

The functional status scores of training were assessed by FIM and Barthel index scores and are presented in Figure 2 and Figure 3, separately. In the training group, both FIM $(28.1 \pm 14.2$ vs $44.6 \pm 10.0, P=.005)$ and Barthel index scores $(4.3 \pm 9.5$ vs $19.3 \pm 18.6, P=.004)$ improved after the exercise training program. In the control group, only post-study Barthel index scores showed significantly greater than pre-study measurements (4.6 \pm 7.9 vs $13.4 \pm 16.6, P=.001)$. The improvement of FIM scores was significantly greater for the training group than the control group $(16.5 \pm 16.5$ vs $4.6 \pm 7.9$, $P=.036)$. However, no significant difference for the improvement of Barthel index scores was found between the 2 groups (Fig. 4). 
Exercise Training in Patients With Prolonged Mechanical Ventilation

Table 2. Effects of Exercise Training Program on Pulmonary Mechanisms in the Training Group, Compared With the Control Group

\begin{tabular}{|c|c|c|c|c|c|c|}
\hline \multirow{2}{*}{$\begin{array}{l}\text { Pulmonary Mechanics } \\
\text { Variables }\end{array}$} & \multicolumn{3}{|c|}{ Training Group } & \multicolumn{3}{|c|}{ Control Group } \\
\hline & Pre-Study & Mid-Study & Post-Study & Pre-Study & Mid-Study & Post-Study \\
\hline$\dot{\mathrm{V}}_{\mathrm{E}}, \mathrm{L} / \mathrm{min}$ & $4.2 \pm 2.7$ & $4.8 \pm 2.6$ & $4.4 \pm 2.1$ & $6.4 \pm 2.8$ & $6.2 \pm 3.0$ & $6.1 \pm 2.9$ \\
\hline $\mathrm{V}_{\mathrm{T}}, \mathrm{mL}$ & $143.6 \pm 79.4$ & $182.2 \pm 89.9^{*}$ & $192.5 \pm 75.0 \dagger$ & $230.0 \pm 95.6 \ddagger$ & $254.8 \pm 108.1$ & $257.6 \pm 125.1$ \\
\hline $\mathrm{P}_{\text {Imax }}, \mathrm{cm} \mathrm{H}_{2} \mathrm{O}$ & $28.3 \pm 17.8$ & $36.7 \pm 26.1$ & $30.9 \pm 24.7$ & $32.1 \pm 15.5$ & $32.0 \pm 6.7$ & $37.4 \pm 14.9$ \\
\hline RSBI & $162.2 \pm 70.1$ & $110.6 \pm 31.5 \mathbb{I}$ & $127.2 \pm 71.2$ & $136.2 \pm 48.8$ & $123.1 \pm 56.2$ & $122.7 \pm 76.3$ \\
\hline $\mathrm{f}$, breaths/min & $24.3 \pm 7.4$ & $21.8 \pm 5.8$ & $21.8 \pm 8.1$ & $27.6 \pm 4.9$ & $25.8 \pm 8.8$ & $24.7 \pm 4.3 \S$ \\
\hline \multicolumn{7}{|c|}{$\begin{array}{l}\text { Values are mean } \pm \mathrm{SD} \\
* P=.043 \text { for the tidal volume difference between pre-study and mid-study within group. } \\
\uparrow P=.02 \text { for the tidal volume difference between pre-study and post-study within group. } \\
\text { II } P=.009 \text { for the RSBI difference between pre-study and mid-study within group. } \\
¥ P=.04 \text { for the tidal volume difference between training and control group. } \\
\S P=.03 \text { for the f difference between pre-study and post-study within group. } \\
\mathrm{V}_{\mathrm{E}}=\text { minute ventilation } \\
\mathrm{V}_{\mathrm{T}}=\text { tidal volume } \\
\mathrm{P}_{\mathrm{Im}}=\text { maximal inspiratory pressure } \\
\mathrm{RSBI}=\text { rapid shallow breathing index } \\
\mathrm{f}=\text { respiratory rate }\end{array}$} \\
\hline
\end{tabular}

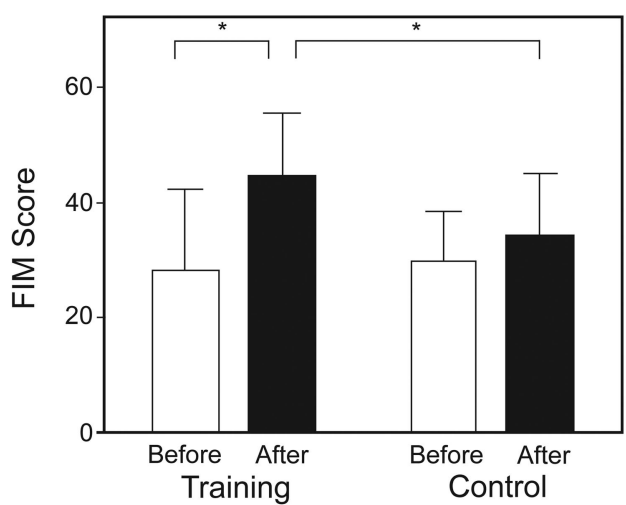

Fig. 2. The effect of exercise training on Functional Independence Measurement (FIM) scores (mean $\pm \mathrm{SD}$ ) in the training and control groups. $P=.005$ for the difference between the pre-study and post-study measurements within the groups. $P=.024$ for the difference between the training and control groups.

\section{RCC Hospitalization Outcomes}

The results of hospitalization outcomes are shown in Table 3. The MV weaning rate for the training group was $75 \%(8 / 12)$ and $53.3 \%$ in the control group (8/15). In the comparison of mortality rate, all subjects in the training group survived during their stay in the RCC, whereas 3 subjects in the control group expired during their RCC stay ( $0 \%$ vs $20 \%, P=.25$ ). The mean duration of RCC stay in the training group was shorter than in the control group ( $35.4 \pm 21.9 \mathrm{~d}$ vs $56.9 \pm 45.6 \mathrm{~d}, P=.10)$. Subjects in the training group also had fewer days on MV $(32.7 \pm 23.4 \mathrm{~d}$ vs $54.6 \pm 46.2 \mathrm{~d}, P=.15)$ than those in the control group. However, neither the difference in RCC stay nor days on MV between groups reached statistical significance.

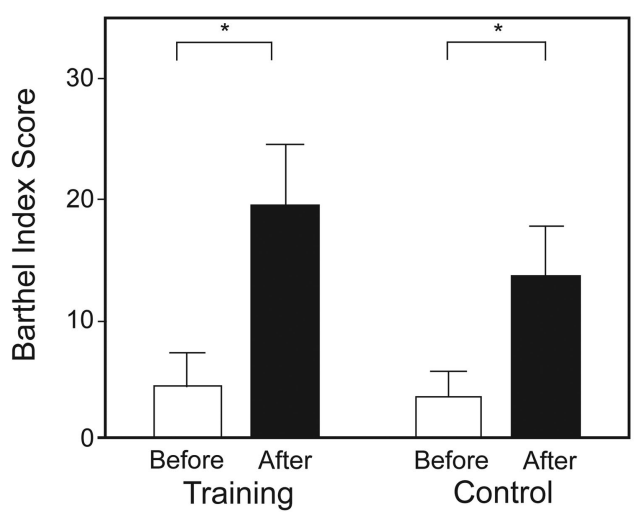

Fig. 3. The effect of exercise training on Barthel Index scores (mean $\pm \mathrm{SD}$ ) in training and control groups. $P=.04$ for the difference between the pre-study and post-study measurements in training groups. $P=.01$ for the difference between the pre-study and post-study measurements in training groups.

\section{Discussion}

In this randomized controlled trial, a daily exercise training program improved pulmonary mechanics in PMV patients by increasing $\mathrm{V}_{\mathrm{T}}$ and decreasing RSBI. Additionally, patients in the exercise training group exhibited greater improvement in functional status after the study period.

Previous research has shown that patients who cannot be weaned from MV often have common clinical characteristics in pulmonary mechanics, such as small $\mathrm{V}_{\mathrm{T}}\left(\mathrm{V}_{\mathrm{T}}\right.$ $<250 \mathrm{~mL}$ ), high respiratory rate, reduced inspiratory muscle strength, and rapid shallow breathing pattern (RSBI > 105). ${ }^{14}$ This may be related to underlying diseases and adverse effects from PMV. ${ }^{15}$ Subjects in our study also presented relatively low $\mathrm{V}_{\mathrm{T}}(143.6 \mathrm{~mL})$ and shallow breathing pattern (RSBI 162.2), suggesting the 


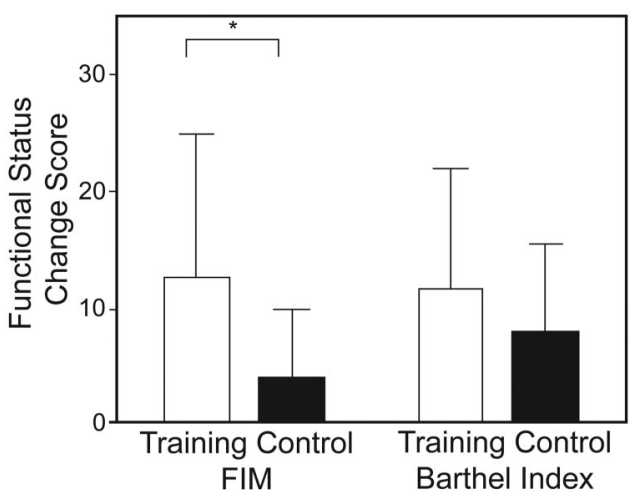

Fig. 4. Comparison of functional status changes (post-study vs pre-study) between the exercise training and control groups. The values are mean $\pm \mathrm{SD} . P=.036$ for the difference between the exercise training and control groups.

presence of ventilation insufficiency at the time they participated in the study. Ventilatory insufficiency can be improved by decreasing respiratory rate, improving respiratory muscle strength, and increasing lung volume through various exercise training programs. ${ }^{16,17}$ Gigliotti et al recruited COPD patients to perform a series of exercise training programs in an out-patient setting, and reported that the subjects' respiratory rate decreased and $\mathrm{V}_{\mathrm{T}}$ increased after training. ${ }^{18}$ In another study examining the effects of respiratory muscle training, Shahin et al showed a significant improvement in respiratory muscle power in subjects after the intervention period. ${ }^{19}$ The participants in our study also demonstrated significant improvement in $\mathrm{V}_{\mathrm{T}}$ and RSBI after receiving the training program. The mechanisms for these improvements are complex. As recommended in the joint American College of Chest Physicians and American Association of Cardiovascular and Pulmonary Rehabilitation statement on pulmonary rehabilitation, ${ }^{20}$ our exercise training program consisted of several components: respiratory muscle training, stretching exercises, and cardiopulmonary endurance exercise training. The respiratory muscle training may help patients increase respiratory muscle strength and breathe more air into their lungs. The stretching exercise and cardiopulmonary endurance exercise may be beneficial in improving lung mechanical efficiency by increasing chest mobility and inducing deep breathing patterns during rest and exercise. The combination of all training stimuli may be optimal for improving pulmonary mechanics and thus lead to increased $\mathrm{V}_{\mathrm{T}}$ and decreased RSBI.

Prolonged immobilization was common in PMV patients and was often associated with major complications, such as atelectasis, skeletal muscle atrophy, and cardiopulmonary dysfunction, that result in decreased ability to perform daily activities..$^{21-23}$ De Jonghe et al examined the relationship between respiratory and limb muscle strength in mechanically ventilated patients in the ICU. They demonstrated that both respiratory muscle strength and lung volume significantly correlated with limb muscle strength, and respiratory muscle weakness is associated with delayed extubation and PMV. ${ }^{24}$ Additionally, early intervention, such as a reconditioning program, would be beneficial for this population to regain functional status independence. In a study of early reconditioning in patients on MV in the ICU setting, Schweicker et al found that subjects in the intervention group had a higher level of functional independence and fewer MV days during the follow-up period than did controls. Thus, the authors suggested that functional status in patients with MV may be improved by a reconditioning program through reversing the side effects of immobilization. ${ }^{25}$ In our study, participants in the training group improved their functional status, presented as FIM and Barthel index scores after the training program. The improvement of FIM scores was also significantly higher in the training group than in the control group. Many studies have pointed out the effectiveness of exercise training in the functional status for patients from various populations. ${ }^{26-29}$ Valderramas et al reported that exercise training resulted in significant improvements in 6-min walking distance and physical function domain of the quality of life questionnaire in patients with COPD. ${ }^{30}$ Pasqua et al investigated the effects of an in-patient exercise training program on patients with respiratory failure, and reported significant improvements in FIM, 6-min walking distance, and quality of life. The authors also found that there is an inverse correlation between dyspnea level and FIM scores, and thus suggested that the improvement of functional status may be related to symptom relief. ${ }^{31}$ As suggested by the report of Casaburi et al, exercise training might improve physical functional status in patients with chronic respiratory diseases, through multiple mechanisms: improving skeletal muscle function and thus deceasing production of blood lactate and ventilatory demand during exercise; improving aerobic capacity by increasing efficiency of oxygen delivery and ventilatory demand; and improving ventilatory efficiency by decreasing respiratory rate and depth of breath during exercise. With the benefits of exercise training, patients are capable of performing a higher level of ADL with lower ventilation demand and fewer symptoms of dyspnea and/or fatigue. ${ }^{3}$

While the outcomes in the training group were better than those of the control group, the difference between the 2 groups was not statistically significant. In our study, subjects in the training group had a higher weaning rate (75\% vs $53.3 \%)$ and a lower mortality rate (0\% vs $20 \%)$ during their RCC stay. The mean RCC hospitalization duration for subjects in the training group ( $36 \mathrm{~d}$ ) was shorter than that for the control group $(57 \mathrm{~d})$. In a multicenter study, Scheinhorn et al examined weaning outcomes in post-ICU ventilated patients, and reported a weaning rate of $54.1 \%$ and a mortality rate of $25 \%$, which are similar to 


\section{Exercise Training in Patients With Prolonged Mechanical Ventilation}

Table 3. Hospitalization Outcomes of the Training and Control Groups During RCC Stay

\begin{tabular}{|c|c|c|c|c|}
\hline Outcome Characteristic & $\begin{array}{l}\text { Training Group } \\
\quad(n=12)\end{array}$ & $\begin{array}{l}\text { Control Group } \\
\quad(n=15)\end{array}$ & $P$ & $\begin{array}{l}\text { Risk Difference } \\
\quad(95 \% \mathrm{CI})\end{array}$ \\
\hline Weaning rate, no. (\%) & $8(75)$ & $8(53.3)$ & .25 & $-0.22(-0.60$ to 0.62$)$ \\
\hline Mortality rate, no. (\%) & $0(0)$ & $3(20)$ & .20 & $0.13(-0.62$ to 0.33$)$ \\
\hline Days of MV dependence, mean $\pm \mathrm{SD}$ & $32.7 \pm 23.4$ & $54.6 \pm 46.2$ & .15 & $-22.9(-52.1$ to 6.0$)$ \\
\hline Days of RCC stay, mean $\pm \mathrm{SD}$ & $35.4 \pm 21.9$ & $56.9 \pm 45.6$ & .10 & $-22.7(-51.1$ to 5.8$)$ \\
\hline
\end{tabular}

the results from our control subjects. ${ }^{1}$ However, the $75 \%$ weaning rate and $0 \%$ mortality rate in our training group are considered to be better outcomes, when compared with previous reports. Although quality of life was not assessed in this study, one can assume that patients in a training group with higher weaning and survival rate may be associated with better quality of life. Various studies have also proved that patients who wean from MV successfully may have better quality of life. In studies examining the difference of 1-year post-ICU quality of life between MV and non-MV users, Charlifue et al reported that non-MV users had better quality of life in the follow-up period. ${ }^{32}$ Douglas et al compared quality of life at 12 months for patients ventilated more than 96 hours to those who underwent PMV. PMV patients had consistently worse overall quality of life than short-term MV patients. ${ }^{33}$ The hospitalization outcomes after an exercise training program in patients with PMV have rarely been reported. Ries et al followed up patients with chronic lung diseases in an outpatient department for a 24-months period, and found that the exercise group had fewer days in hospital than the control group. ${ }^{34}$ Unfortunately, the difference was not statistically significant due to the small sample size. The similar results of both Ries et al and the present study suggest the possibility that exercise training could help patients with chronic lung diseases to improve their outcomes, not only in the out-patient setting but also in subacute care units such as an RCC.

There were some limitations to this study that should be considered when interpreting the results. First, there were baseline differences in some pulmonary mechanics measures between groups. The control group had larger lung volumes and higher respiratory rate than the training group at baseline, which may possibly be large enough to influence the final outcomes to a clinically meaningful degree. Our study did not account for the severity of illness, length of previous ICU stay, or etiologies for requiring PMV, all of which could contribute to group differences over time. Randomization in a further study that includes matching diagnosis and disease severity may ensure that the groups are comparable on the baseline and outcome measures.
Another limitation is the relative small sample size and lack of statistical power in detecting the differences in some outcome measures between groups. Since functional status was the primary outcome in this study, the sample size was calculated based on detecting a difference in FIM scores with $80 \%$ power and a $P$ value $<.05$. However, this sample size may be insufficient to show a between-group difference in secondary outcomes such as hospitalization outcomes, considering their different characteristics. In addition, there was an unexpected loss of subjects due to acute onset of pneumonia and poor adherence by participants, which may be related to the effects of exercise training, further contributing to a low statistical power. Future studies with larger sample size are needed to discuss the effects of exercise training on complications and discharge status.

\section{Conclusions}

A comprehensive exercise training program consisting of both cardiopulmonary endurance and peripheral muscle training is beneficial for patients on PMV in an RCC. The benefits include the improvement of pulmonary mechanics and physical functional status. Whether such exercise training programs can improve RCC hospitalization outcomes, such as increasing mechanical ventilator weaning rate and/or decreasing hospitalization duration in PMV patients, awaits further larger scale studies.

\section{REFERENCES}

1. Scheinhorn DJ, Hassesnpflung MS, Votto JJ, Chao CC, Epstein SK, Doig GS. Post-ICU mechanical ventilation at 23 long-term care hospitals: a multicenter outcomes study. Chest 2007;131(1):85-93.

2. De Jonghe B, Bastuji-Garin S, Drand MC. Respiratory muscle weakness is associated with limb weakness and delayed weaning in critical illness. Crit Care Med 2007;35(9):2007-2015.

3. Casaburi R, ZuWallack R. Pulmonary rehabilitation for management of chronic obstructive pulmonary disease. N Engl J Med 2009; 360(13):1329-1335.

4. Nici L, Raskin J, Rochester CL, Bourbeau JC, Carlin BW, Casaburi $\mathrm{R}$, et al. Pulmonary rehabilitation: what we know and what we need to know. J Cardiopulm Rehabil Prev 2009;29(3):141-151. 


\section{Exercise Training in Patients With Prolonged Mechanical Ventilation}

5. Costi S, Crisafulli E, Antoni FD, Beneventi C, Fabbri LM, Clini EM. Effects of unsupported upper extremity exercise training in patients with COPD: a randomized clinical trial. Chest 2009;136(2):387-395.

6. Mador MJ, Krawza M, Alhajhusian A, Khan AI, Shaffer M, Kufel $\mathrm{TJ}$, et al. Interval training versus continuous training in patients with chronic obstructive pulmonary disease. J Cardiopulm Rehab Prev 2009;29(2):126-132.

7. Clini E, Foglio K, Bianchi L, Porta R, Vitacca M, Ambrosino N. In-hospital short-term training program for patients with chronic airway obstruction. Chest 2001;120(5):1500-1505.

8. Mahoney FI, Barthel DW. Functional evaluation: the Barthel Index. Md State Med J 1965;14(2):61-65.

9. Data management service of the uniform data system for medical rehabilitation and the center for functional assessment research. Guide for use of the uniform data set for medical rehabilitation including the functional independence measure (version 3.1). Buffalo, NY: SUNY; 1990.

10. Deutsch A, Fiedler RC, Iwanenko W, Granger CV, Russel CF. The uniform data system for medical rehabilitation report: patients discharged from subacute rehabilitation programs in 1999. Am J Phys Med Rehabil 2003;82(9):703-711.

11. Hsueh IP, Lee MM, Hsieh CL. Psychometric characteristics of the Barthel Activities of Daily Living Index in stroke patients. J Formos Med Assoc 2001;100(8):526-532.

12. Hamilton BB, Laughlin JA, Fiedler RC, Granger CV. Interrater reliability of the 7-level Functional Independence Measure (FIM). Scan J Rehabil Med 1994;26(3):115-119.

13. Dodds TA, Mrtin DP, Stolov WC, Deyo RA. A validation of the functional independence measurement and its performance among rehabilitation inpatients. Arch Phys Med Rehabil 1993;74(5):531536.

14. Yang KL, Tobin MJ. A prospective study of indexes predicting the outcome of trials of weaning from mechanical ventilation. $\mathrm{N}$ Engl J Med 1991;324(21):445-1450.

15. Purro A, Appendini L, De Gaetano A, Gudjonsdottir M, Donner CF, Rossi A. Physiologic determinants of ventilator dependence in longterm mechanically ventilated patients. Am J Respir Crit Care Med 2000;161(4 Pt1):115-1123.

16. Cooper CB. Exercise in chronic pulmonary disease: limitations and rehabilitation. Med Sci Sports Exerc 2001;33(Suppl 7):S643-S646.

17. Clini E, Ambrosino N. Eary physiotherapy in the respiratory intensive care unit. Respir Med 2005;99(9):1096-1104.

18. Gigliotti F, Coli C, Bianchi R, Romagnoli I, Lanini B, Binazzi B, et al. Exercise training improves exertional dyspnea in patients with COPD: evidence of the role of mechanical factors. Chest 2003; 123(6): 1794-1802.

19. Shahin B, Germain M, Kazem A, Annat G. Benefits of short inspiratory muscle training on exercise capacity, dyspnea, and inspiratory fraction in COPD patients. Int J Chron Obstruct Pulmon Dis 2008; 3(3):423-427.
20. Ries AL, Bauldoff GS, Carlin BW, Casaburi R, Emery CF, Mahler DA, et al. Pulmonary Rehabilitation: joint ACCP/AACVPR evidence-based clinical practice guidelines. Chest 2007;131(Suppl5): $4 \mathrm{~S}-42 \mathrm{~S}$

21. Levine S, Nguyen T, Taylor N, Taylor N, Friscia ME, Budak MT, Rothenberg P, et al. Rapid disuse atrophy of diaphragm fibers in mechanically ventilated humans. N Engl J Med 2008;358(13):13271335.

22. Schweickert WD, Hall J. ICU-acquired weakness. Chest 2007;131(5): 1541-1549.

23. Jubran A. Critical illness and mechanical ventilation: effects on the diaphragm. Respir Care 2006;51(9):1054-1061.

24. De Jonghe B, Sharshar T, Lefaucheur JP, Authier FJ, DurandZaleski I, Boussarsar M, et al. Paresis acquired in the intensive care unit: a prospective multicenter study. JAMA 2002;288(22):28592856.

25. Schweicker WD, Pohlman MC, Pohlman AS, Nigos C, Pawlik AJ, Esbrook CL, et al. Early physical and occupational therapy in mechanically ventilated, critically ill patients:a radomised controlled trial. Lancet 2009;373(9678):1874-1882.

26. Theander K, Jakobsson P, Unosson M. Effects of pulmonary rehabilitation on fatigue, functional status and health perceptions in patients with chronic obstructive pulmonary disease: a randomized controlled trial. Clin Rehabil 2009;23(2):125-136.

27. Laviolette L, Bourbeau J, Lacasse Y, Pepin V, Breton MJ, Baltzan $\mathrm{M}$, et al. Assessing the impact of pulmonary rehabilitation on functional status in COPD. Thorax 2008;63(2):115-121.

28. Gravey C. Interstitial lung disease and pulmonary rehabilitation. J Cardiopulm Rehabil Prev 2010;30(3):141-146.

29. Sundararajan J, Balami J, Packham S. Effectiveness of outpatient pulmonary rehabilitation in elderly patients with chronic obstructive pulmonary disease. J Cardiopulm Rehabil Prev 2010;30(2):121-125.

30. Valderramas SR, Atallah AN. Effectiveness and safety of hypertonic saline inhalation combined with exercise training in patients with chronic obstructive pulmonary disease: a randomized trial. Respir Care 2009;54(3):327-333.

31. Pasqua F, Biscione GL, Crigna G, Gargano R, Cardaci V, Ferri L, et al. Use of functional independence measure in rehabilitation of inpatients with respiratory failure. Respir Med 2009;103(3):471-476.

32. Charlifue S, Apple D, Burns SP, Chen D, Cuthbert JP, Donovan WH, Lammertse DP, et al. Mechanical ventilation, health, and quality of life following spinal cord injury. Arch Phys Med Rehabil 2011;92(3):457-463.

33. Douglas SL, Daly BJ, Gordon N, Brennan PF. Survival and quality of life: short-term versus long-term ventilator patients. Crit Care Med 2002;30(12):2655-2662.

34. Ries AL, Kaplan RM, Myers R, Prewitt LM. Maintenance after pulmonary rehabilitation in chronic lung disease: a randomized trial. Am J Respir Crit Care Med 2003;167(6):880-888. 